\title{
INTEGRATED USE OF REMOTE SENSING, GIS AND GPS TECHNOLOGY FOR MONITORING THE ENVIRONMENTAL PROBLEM OF SHYAMNAGAR
}

\author{
M.S. Akbar ${ }^{\mathrm{a}}$, M.H. Sarker ${ }^{\mathrm{a}}$, M.A. Sattar, G.M. Sarwar ${ }^{\mathrm{a}}$, S.M.M Rahman ${ }^{\mathrm{b}}$, M.M. Rahman ${ }^{\mathrm{a}}$, Z.U Khan $^{\mathrm{a}}$, \\ ${ }^{a}$ National Land use Project, Ministry of Land, Bhumi Bhaban Complex, Nilkhet, Dhaka-1205, Bangladesh \\ mhsarker2@yahoo.com; Mahbub_geo@y ahoo.com \\ ${ }^{\mathrm{b}}$ Bangladesh Space Research and Remote Sensing Organization (SPARRSO) \\ Begum Rokeya Sarani, Agargaon, Dhaka-1207, Bangladesh \\ mizan.sparrso@yahoo.com
}

KEY WORDS : Environmental disaster, Shrimp, Agriculture, Remote Sensing, GIS, GPS, Classifications.

\begin{abstract}
ABS TRACT:
Cultivation of shrimp mostly in unplanned way has been considered as one of the major environmental disasters of Shamnagar. Villagers surrounding the rivers are mainly involved with fish (shrimp) cultivation. So, fertile agriculture land has been converted to shrimp cultivation. Conversion of agriculture land to other usage is a common but acute problem for land resources of the country like Bangladesh. Conventional methods for collecting this information are relatively costly and time consuming. Contrarily, Remote Sensing satellite observation with its unique capability to provide cost-effective support in compiling the latest information about the natural resource. Remote sensing, in conjunction with GIS, has been widely applied and been recognized as a powerful and effective tool in detecting land use and land cover changes. RapidEye, Landsat 8 images were used to identify land use and land cover of the area during the period 2008 and 2015. Google images were used to identify the micro-level land use features of the same period. Multi-spectral classifications using unsupervised and supervised classification were done and results have been compared based on the field investigation. The study reveals that during the period 2008 to 2015 agricultural practice has been reduced from $35 \%$ to $21 \%$ and shrimp cultivation area increased from $38 \%$ to $50 \%$. Due to the impact of high salinity and salt water intrusion caused by natural disaster, agricultural activities is reduced and farmers have been converted to other practices, as a result shrimp farming is gaining popularity in the area.
\end{abstract}

\section{INTRODUCTION}

Shy amnagar is an upazila (sub-district) of Satkhira District. It is one of the most vulnerable upazila of Bangladesh coast. Disasters like cyclone and monsoon storm surges, salinity intrusion, river bank erosion, degradation of wetland ecosystems, expansion of settlement, infrastructure and industries are the major environment issues addressed in the upazila. Salinity in the river system increases steadily from December through February, reaching maximum in the late March and early April. This is the high time for shrimp cultivation.

Generally, cultivation of shrimp mostly in unplanned way in Shyamnagar upazila has been considered as one of the major environmental disasters that basically happened because of its introduction aiming to prompt increase the economy of the country. But unfortunately, this has been practiced in an unregulated manner as it happened to Shy amnagar, the shrimp cultivation field should be left undisturbed for 10-15 years allowing sufficient time for the replenishment of soil and regeneration of vegetation in the area. Ironically, excessive human pressure does not allow this time period (10-15 years). As a result, shrimp cultivation has been identified as a major cause of environmental imbalance in Shyamnagar. Villagers surrounding the rivers are mainly involved with fish cultivation. So, fertile agriculture land has been converted to shrimp cultivation. Agriculture land was also converted into brickfields. Conversion of agriculture land to other usage is a common but acute problem for land resources of the country. Therefore land degradation, natural resource conservation and shrimp cultivation with agricultural practice should be done in a planned way which can help to protect natural ecosystem and improve socio-economic condition of the local people of Shy amnagar.
Conventional methods for collecting this information are relatively costly and time consuming. Contrarily, Remote Sensing (RS) satellite observation with its unique capability to provide time-saving and cost-effective support in compiling the major information source extracting natural features in landscape repeatedly (Stach,N et al 2007). RS technique has ability to represent of land use/land cover analy sis by means of digital classification process of multispectral satellite image (Campbell, J.B. 1996). GIS is a computer supported system to efficiently capture, store, update, manipulate and analyze of spatial information for land cover feature identification and finally produce maps of all variables were combined to extract information for better understanding (Weng, 2001, ArcGIS user guide). Satellite remote sensing, in conjunction with GIS, has been widely applied and been recognized as a powerful and effective tool in detecting land use and land cover changes. It is a potential tool to study change in land cover, forest density, coastal morphology, status of reef and biodiversity of islands even if, located in remote place.

Several types of satellite images have been collected to generate the land use changes using RS, GPS and GIS technologies. A combination of land use data of different time period derived from several satellite images and field level land use information are used to land use and land cover changes. In this study RapidEye satellite images serves as a major information source extracting natural features in land use of Shyamnagar Upazila. Dry season of RapidEye images were used to identify land use and land cover of the area during the period 2008 and 2015. A number of moderate resolution satellite images such as Landsat8-OLI (Operational Land Imager) were used to delineate the winter crops; Sentinel-MSI (Multi Spectral Imager) images were used to understand broad cropping pattern and seasonal land cover like Monsoon Crop 
(Aman) and Google images were used to identify the microlevel land use fetures of same period.

In the present study, an attempt has been made to identify the major environmental factors of Shy amnagar Upazila's derived from remote sensing, GIS, GPS technologies as well as people participatory approach during the period 2008 to 2015.

\section{MATERIALS AND METHODS}

\subsection{Study Area}

Shyamnagar Upazila (Satkhira district) area $1968.24 \mathrm{sq} \mathrm{km}$ (including 1485.13 Sundarbans and 483.11sq.km mainland, ie study area), located in the south-western part of Bangladesh between $21^{\circ} 36^{\prime}$ and $22^{\circ} 24^{\prime}$ north latitudes and in between $89^{\circ} 00^{\prime}$ and $89^{\circ} 19^{\prime}$ east longitudes. It is bounded by kaliganj and Assasuni upazilas (Satkhira district) on the north, the Bay of Bengal on the south, Koyra upazilas (Khulna District) on the east, West Bengal state of India on the west. Figure 1 shows the study upazila in Bangladesh administrative map and figure 2 shows the study area in Shyamnagar upazila including sundarbans.

Shyamnagar, the largest Upazila of Satkhira District in respect of area, came into existence as a thana (Police Station) in 1897 and was upgraded to Upazila (Sub-district) in 1982. Sundarbans, the largest single block tidal mangrove forest in the world lies in Shyamnagar Upazila. It is a UNESCO world Heritage site recognized and legally protected by international treaties as a universally protected zone. Sundarban is also named as Ecologically Critical Area (ECA) because it continues to suffer from over-exploitation and illegal encroachment. To control the natural environment and ecosystem, $10 \mathrm{~km}$ area surrounding Sundarbans has been restricted as ECA by the Government of Bangladesh. According to this notification $70 \%$ area of Shy amnagar Upazila has fallen under ECA.

The Upazila is connected with Sadar and Satkhira District town and internally with other unions by metaled \& semi metaled roads. The main rivers flowing through the Upazila are: Raymangal, Kalindi, Kobadak, Kholpetua, Arpangachhia, Malancha, Hariabhanga and Chuna. This area is also ecologically rich because of the combination of coastal mangrove forests, tidal estuaries, productive agricultural lands, and economic activities such as shrimp farming, crab harvesting and crab fattening. Agriculture with shrimp farming is considered as major livelihood of the area and the main export items are fish (shrimp) and honey.

The people of the Upazila are prone to floods, cy clones, salinity intrusion and droughts, and the incidence of these hazards is rising. Water and soil salinity are normal hazards of the Upazila, affecting different uses of water including irrigation, drinking, household, fisheries, and functioning of the ecosystem. Salinity in the river system increases steadily from December through February, reaching maximum in the late March and early April. The impact of salinity on crop production as well as on aquatic environment is well documented.

\subsection{Data Collection}

An inventory and evaluation of Shyamnagar upazila has been conducted during the period 2008 and 2015. In this period land use pattern, social and environmental appraisals have been conducted up to the union level (small administrative unit). The unions lying under the broader zones and sub-zones were demarcated. Assessment and people participatory appraisal of data collected from different aspects. Both qualitative and quantitative types of data were also collected. Collection of data are split into two major types namely Primary and Secondary data. Brief data collection steps are given below:

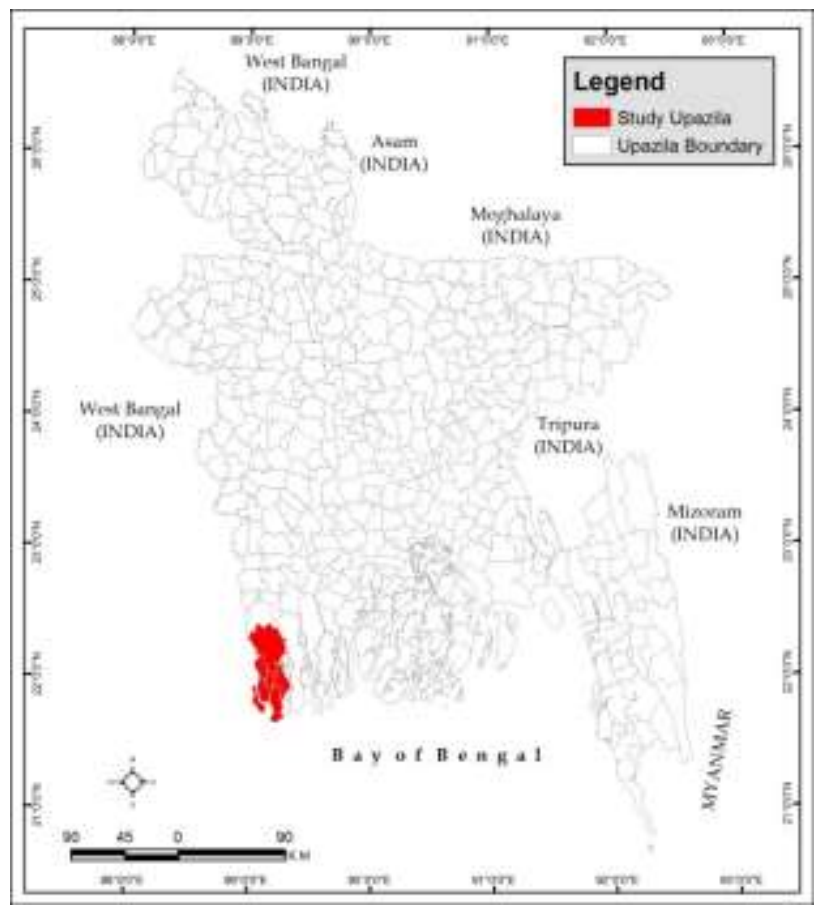

Figure 1. Study Upazila in Bangladesh administrative map

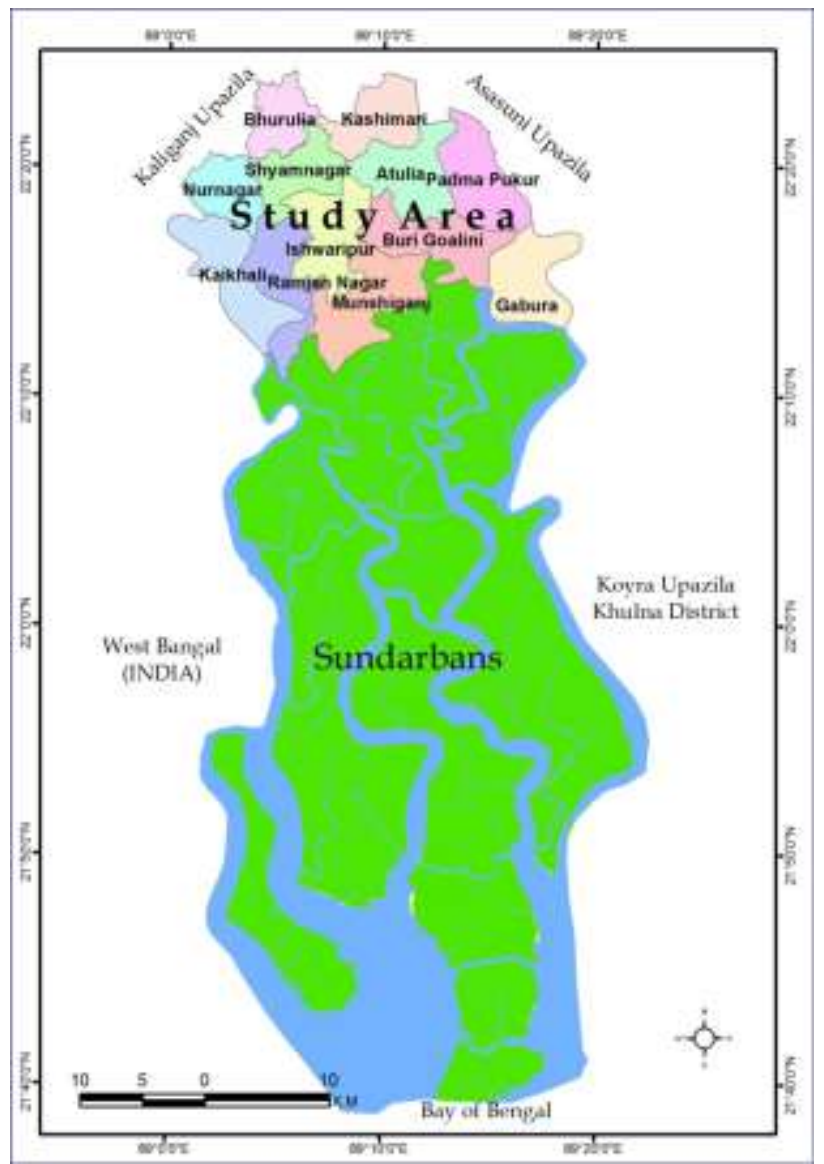

Figure 2. Study area in Shy amnagar upazila including Sundarban area

a) Primary Data 
- Satellite imageries.

- $\quad$ GPS data collected during field survey.

- Exchange views with the Bangladesh Rural Development Board (BRDB) for land use of agriculture, fisheries and forestry and environment departments' officials of union and upazila level.

\section{b) Secondary Data}

- Administrative boundaries collected from the Centre for Environmental Geographic Information Services (CEGIS).

- Soil map/data collected from Soil Resource Development Institute (SRDI), Bangladesh.

\subsection{Satellite Images}

Several types of satellite images have been collected to generate the land use changes using RS, GPS and GIS technologies. A combination of land use data of different time period derived from several satellite images and field level land use information are used to land use and land cover changes. In this study RapidEye satellite images serves as a major information source extracting natural features in land use of Shyamnagar Upazila. Dry season of RapidEye images were used to identify land use and land cover of the area during the period 2008 and 2015. A number of moderate resolution satellite images such as Landsat8-OLI (Operational Land Imager) were used to delineate the winter crops, Sentinel-MSI (Multi Spectral Imager) images were used to understand broad cropping pattern and seasonal land cover like Monsoon Crop (Aman) and Google images were used to identify the microlevel land use features of the same period.

Table-1: Satellite images and its characteristics used in the study

\begin{tabular}{|c|c|c|c|c|c|}
\hline gentar. & Sen- & 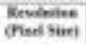 & thatrat & 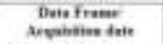 & 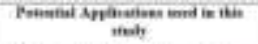 \\
\hline Tastilen & $\mathrm{Nal}$ & 5it & 5 & 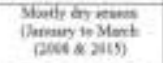 & 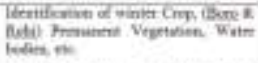 \\
\hline Latheng & TM & $9=$ & 7 & 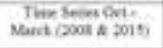 & 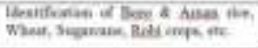 \\
\hline Lankatit & का & $12 \times 0=1$ & 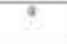 & 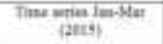 & 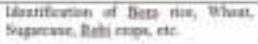 \\
\hline inatiant & Mon & 10000 & DI & $\begin{array}{l}\text { Oetider-Deschber } \\
\text { can-s anh }\end{array}$ & 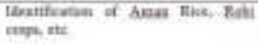 \\
\hline 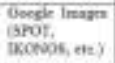 & & $1.4 n$ & & In trans & 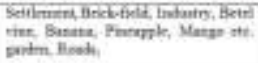 \\
\hline
\end{tabular}

Sources: website of respective satellite vendors and ERDAS Tour Guide

\subsection{GPS data}

Global Positioning System (GPS) is a USA space-based navigation system that provides reliable positioning, navigation, and timely services to worldwide users on a continuous basis in all weather, day and night. It also provides three-dimensional locations plus precise time (Richharia, M 2003). In this study a handheld GPS (Germin) was used to collect the Ground Control Point (GCP) for geo-referencing the remotely sensed data as well as field verification of land use data interpretation. Easily identifiable points such as, road crossing, end of a bridge, corner of a building, etc. were used as reference points. Other application of GPS was to locate the geographical position of the Important/Tourist places as well as administrative headquarters etc. of the study area. Rectified images and the point data collected from GPS were then integrated into a GIS database. Figure 3 shows the integration of GPS, RS and GIS.

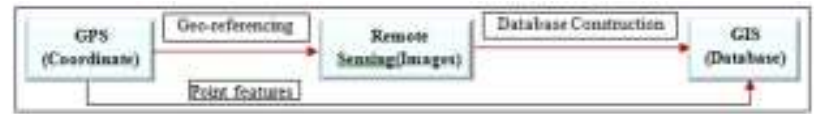

Figure 3. Integration of GPS, RS and GIS

\subsection{Software Used}

a) ERDAS-imagine (v2013)

b) ArcGIS (v10.2.1 and v10.3.1)

c) MS-Excel and Access

\section{METHODOLOGY}

\subsection{Data processing}

Land use and land cover changes involves data pre- processing (geo-referencing, sub-setting, etc.), thematic layer generation (land use classes), data analysis, field validation, arrange workshop and finally produce land use changes of the study period.

\section{2 Geo-referencing}

Many geo-referencing methods have been used to georeference multi-spectral satellite imagery (ERDAS imagineuser guide). One of the methods is collection of Ground Control Point (GCP) from study area using Global Positioning System (GPS). In this method GCP collected from study area and transformed this geographical coordinate to multi-spectral satellite image (same area images) by using geometric model of ERDAS imagine software. In geo-referencing/re-sampling method Bangladesh Transverse Mercator (BTM) projection system was used. Second order polynomial method and nearest neighbor image resampling algorithm was applied for the geometric correction of satellite images. The RMS error of the was in a range of 0.1 to 0.45 pixels.

\subsection{Data Generation}

The multi satellite and multispectral imagery has been used which helps identification of perennial and seasonally varying features of land-use. The RGB false colour composite has been prepared for visualizing the land features. For visual interpretation tone, texture, pattern, shape and size have been considered. Then the multi-spectral classification using unsupervised (ISODATA) and supervised classification (Parallelepiped and Maximum Likelihood techniques) were done and results have been compared. Based on remote sensing, field investigation and secondary data, the entire study area had been classified in details into several thematic layers/features. Afterward, the thematic layers were clustered into following classes shown in Table 2.

Table 2. Detailed generated and clustered thematic layers used in the study

\begin{tabular}{|c|c|c|c|}
\hline $\begin{array}{l}\text { Feastern } \\
\text { Iype }\end{array}$ & Derailhd Genersod Themade Lwen. & $\begin{array}{l}\text { Feamurv } \\
\text { Iype }\end{array}$ & Clewerned Thrastic Leges \\
\hline Polypun & 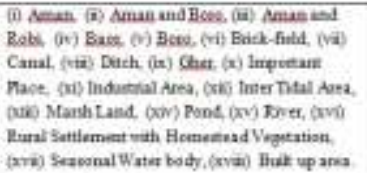 & Powpin & 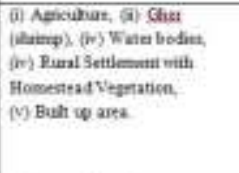 \\
\hline the & Iramegon Netmede & Lent: & traspon Netwerk: \\
\hline Penet & 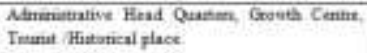 & Pronit & 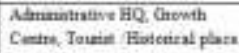 \\
\hline
\end{tabular}

The supervised classification using maximum likelihood provides best results for land use. The major classes such as forest, homestead vegetation, water bodies, urban/built-up areas and crop lands have been identified through interpretation of the classified imagery. 
Field information data was collected from Bangladesh Rural Development Board (BRDB). Micro-level features such as canals, roads, small homestead, etc. generated from Google (SPOT, IKONOS, etc.) images and aerial photographs. Different steps of data generations are shown in Figure 4

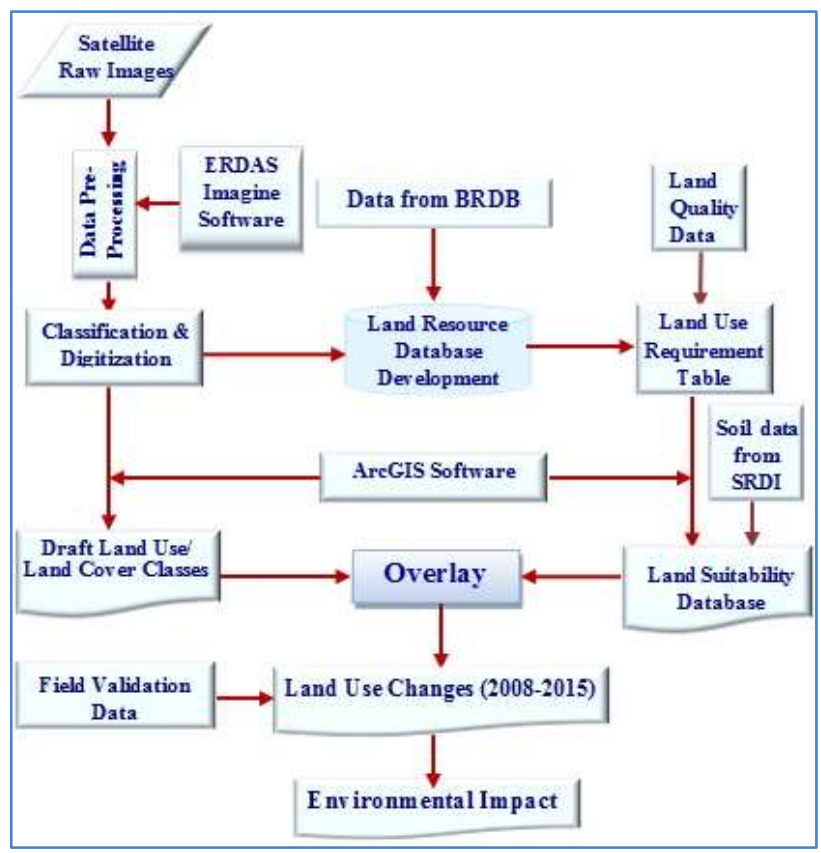

Figure 4. Steps of data generations

\section{RES ULT AND ANALYSIS}

\subsection{Result}

Both supervised and unsupervised classification techniques have been applied for the image of 2008 and 2015. The major land use classes are found almost similar in both the techniques. Table 3 shows the major classified land use areas during the period 2008 and 2015 based on satellite data and table 4 shows the details statistics based on satellite as well as field information and secondary data. Figure $5 \mathrm{c}$ and table 3 shows the major land use changes during the period 2008 to 2015.

Table 3. Major land use areas during the period 2008 and 2015

\begin{tabular}{|c|c|c|c|c|c|}
\hline \multirow[t]{2}{*}{$\begin{array}{l}\text { Major Land } \\
\text { Cse }\end{array}$} & \multicolumn{2}{|c|}{$\begin{array}{l}\text { Supervised Classificatiou } \\
\text { Area (ha) and (9\%) }\end{array}$} & \multicolumn{2}{|c|}{$\begin{array}{c}\text { tal-Supervised Classification } \\
\text { Area (ha) and (5o) }\end{array}$} & \multirow{2}{*}{$\begin{array}{l}\text { Remartas } \\
\text { Gepercilied } \\
\text { dasilification) }\end{array}$} \\
\hline & 2008 & 2015 & 2005 & 2015 & \\
\hline $\begin{array}{l}\text { Agrikalinury } \\
\text { LaadT_Ames }\end{array}$ & $\begin{array}{l}16105 \\
\text { 9556) }\end{array}$ & $\begin{array}{l}\text { की5श } \\
\text { (210) }\end{array}$ & $\begin{array}{l}\text { 16-1010 } \\
\text { (346) }\end{array}$ & $\begin{array}{l}9 / 17 \\
(226)\end{array}$ & 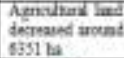 \\
\hline $\begin{array}{l}\text { Gbeeshriesp } \\
\text { Area }\end{array}$ & $\begin{array}{l}17301 \\
(9854)\end{array}$ & $\begin{array}{l}22816 \\
(5046)\end{array}$ & $\begin{array}{l}17311 \\
(396)\end{array}$ & $\begin{array}{l}22810 \\
(3005)\end{array}$ & $\begin{array}{l}\text { Shrmp ber } \\
\text { teassol }\end{array}$ \\
\hline $\begin{array}{c}\text { Rural } \\
\text { Suttlement }\end{array}$ & (1956) & $\begin{array}{l}7281 \\
\text { (164) }\end{array}$ & $\begin{array}{l}7009 \\
(1590)\end{array}$ & $\begin{array}{l}7280 \\
0659\end{array}$ & thoreased \\
\hline Water bodin & 3205 & $\begin{array}{l}3084 \\
\text { ait*v }\end{array}$ & $\begin{array}{l}32,99 \\
0240\end{array}$ & $\begin{array}{l}3014 \\
(116)\end{array}$ & Decanand \\
\hline $\begin{array}{l}\text { Beilt up ares } \\
\text { (Crtas Arte) }\end{array}$ & $\begin{array}{l}3203 \\
0.0746)\end{array}$ & $\begin{array}{l}32.05 \\
(0.976)\end{array}$ & $\begin{array}{l}3205 \\
(0.076)\end{array}$ & $\begin{array}{l}3201 \\
(0.0796)\end{array}$ & No changed \\
\hline
\end{tabular}

\subsection{Analysis}

In figure 5a (land use 2008), it is clearly seen (visual) that $\mathrm{T}$. Aman (green colour) shows more areas in 2008 compare to 2015 in figure $5 \mathrm{~b}$. In table 3 shows the Agriculture land area (ha) more in 2008 compare to 2015 both supervised and unsupervised classes. On the other hand shrimp areas (magenta colour) shows less in 2008 (figure 1a) compare to 2015 (figure $5 \mathrm{~b}$ ). In figure $5 \mathrm{c}$ (red colour) shows T. Aman (monsoon rice) converted to Shrimp (Gher) culture. Table 3 shows the area (ha) and percentage (\%) both the year in agriculture and shrimp. From table 3 and figure $5 \mathrm{c}$ shows that major changes are observed between Agriculture and Shrimp. Others land use found little change or almost same during both the period. The agriculture land use converted to shrimp around 6351 hectors shown in table 3 .

Table 4. Union-wise statistics during the period 2008 and 2015

\begin{tabular}{|c|c|c|c|c|c|c|c|}
\hline 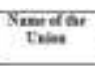 & $\begin{array}{l}\text { Teal } \\
\text { met ave } \\
\text { mate }\end{array}$ & 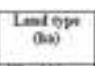 & Thas & sब & $\begin{array}{l}\text { Balkatsing } \\
\text { Dows }\end{array}$ & Land ancke & 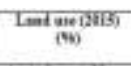 \\
\hline Sinth & aอ & 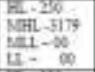 & Cuention & 然. & 4: & 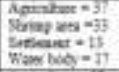 & 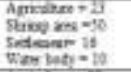 \\
\hline Shunit & teet & 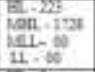 & aritim & $\mathrm{s}^{\mathrm{s}}$ & u & 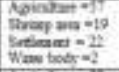 & 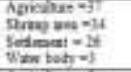 \\
\hline Bari Goatai & en & 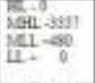 & dar ber & $\frac{13}{39}$ & 14:s & 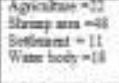 & 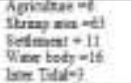 \\
\hline Gatun & 9988 & 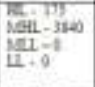 & Clay & $\frac{35}{3, a}$ & $18: 15$ & 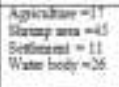 & 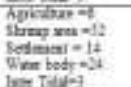 \\
\hline lisnabe & $2 \pi 4$ & 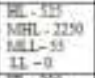 & ans & ss & 10.98 & 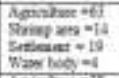 & 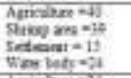 \\
\hline Katana & S4A & 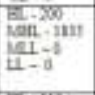 & Inoplat & is & 1030 & 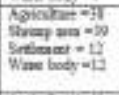 & 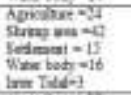 \\
\hline Kantanari & spo & 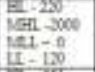 & are kem & 50 & s.12 & 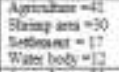 & 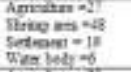 \\
\hline Siestitianal & (1) & 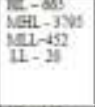 & 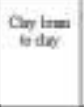 & 35 & last & 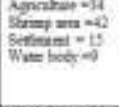 & 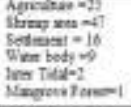 \\
\hline Xumesure & 27v & 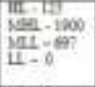 & Set & $\frac{59}{60}$ & $4-12$ & 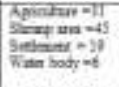 & 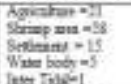 \\
\hline $\begin{array}{l}\text { Palen } \\
\text { Batur }\end{array}$ & "nsh & 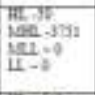 & ang & $\frac{35}{3 a}$ & $14: 25$ & 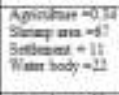 & 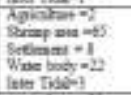 \\
\hline 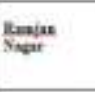 & mи & 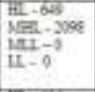 & $\begin{array}{c}\text { Gylawi } \\
\text { xide }\end{array}$ & is & 10.3n & 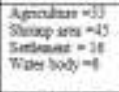 & 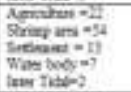 \\
\hline stonanger & 391 & 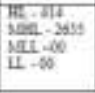 & 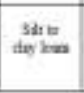 & 60 & 202 & 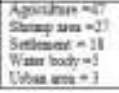 & 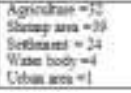 \\
\hline
\end{tabular}

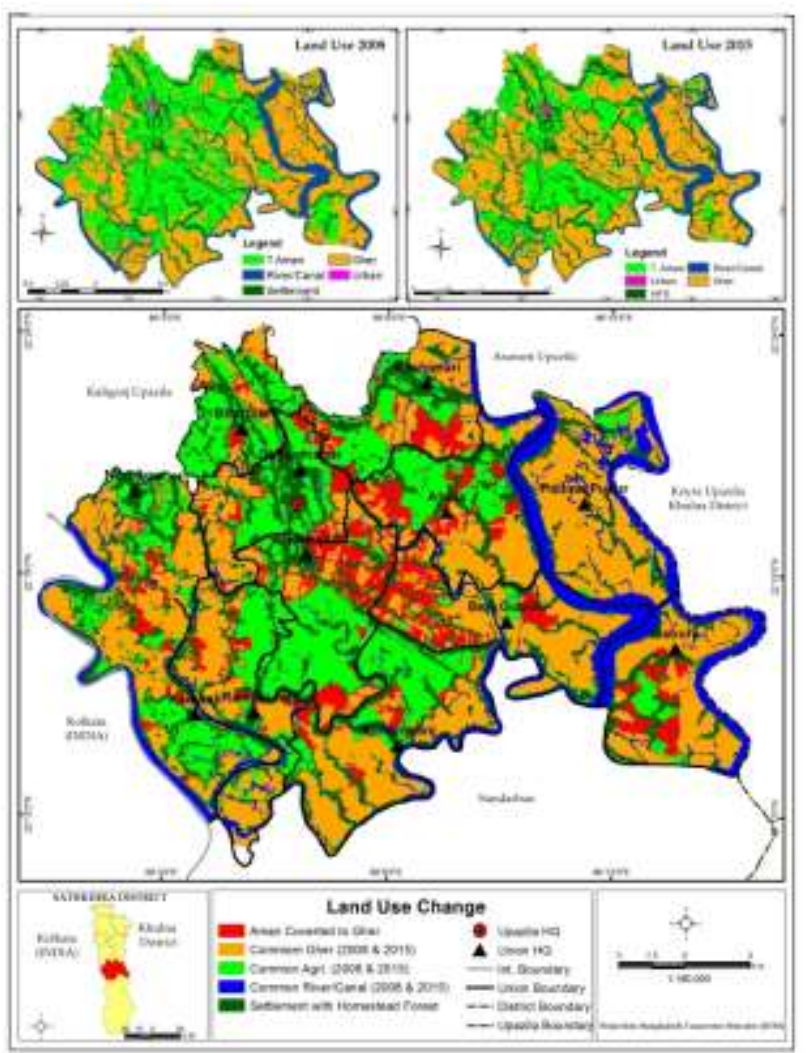

Figure 5. Land use change detection map during 2008- 2015 
It is clearly seen from the table 4 that except Padma pukur union all other unions shows increase of shrimp areas by decrease of Agriculture land. The increasing rate was observed $3 \%$ to $18 \%$. More increasing activities $(25 \%)$ was found in Ishwaripur union and less was $3 \%$ in Nurnagar union. Shrimp culture activity in Padma pukur union observed $67 \%$ and $65 \%$ in 2008 and 2015 respectively. Field observation shows that the decrease of shrimp activity in Padma pukur union due to long time cultural of same species. It is noted that, shrimp culture activities was started in Shyamnagar upazila by Padma pukur union. From change detection analysis it is clearly seen that environmental impact have been detected due to increase of shrimp culture activities. Other causes are analy zed bellow:

\subsubsection{Cyclone and Tidal Surge}

The upazila is frequently affected by natural disaster like cyclones and tidal surges formed in the Bay of Bengal. Shyamnagar Upazila is highly vulnerable to cyclone and tidal surges because of its geographic location on the seafront side of the district. Since 1770, at least 25 major cyclones landed in this belt resulting in significant loss of lives and properties.

Severe cyclone Sidr hit the coastal area on 15 November 2007 caused serious damage to the life and properties of this upazila. Sidr made landfall on the Bangladesh coast on 15 November 2007 (GoB 2008, Sarwar 2016). It was a category-4 cyclone of

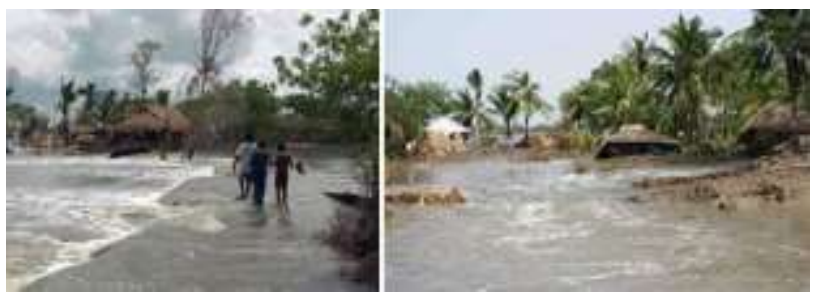

Figure 6. Devastating photographs of Cyclone Aila

$1,000 \mathrm{~km}$ diameter with wind speed of $240 \mathrm{~km} / \mathrm{hour}$ that ravaged the southwest coastal zone. Shyamnagar upazila was highly affected the cyclone. Cyclone Aila also affected the southwest coast of Bangladesh on 25 May 2009. The maximum sustainable wind speed within $54 \mathrm{~km}$ of the storm center was about $80 \mathrm{KPH}$ rising to $100 \mathrm{KPH}$ in gusty and squirrel wind on 25 May 2009. $110 \mathrm{KPH}$ (3-minute sustained) and $120 \mathrm{KPH}$ (1minute sustained) during peak intensity (Sarker M. H 2013b).

At least 172 men were killed (UNB) by the influence of cyclone Aila. The Aila in the costal belt washed away embankments at more than 150 points along the coast. Most of the low-lying areas of the coastal districts including satkira of Shy amnagr were inundated by storm surge of height 06-10 feet above normal astronomical tide. Hundreds of thousands of people living in offshore islands, chars and remote areas of Khulna, Barisal, Patuakhali, Bagerhat, Borguna, Satkhira, Barisal, Bhola, Pirojpur, Jhalokathhi, Laxmipur, Noakhali, Feni, Chandpur, Chittagong and Cox's Bazaar were trapped by tidal water. Samples of devastating photographs are shown in figure 6 in Shy amnagar upazila.

\subsubsection{Salinity}

Salinity intrusion is a major problem in Shyamnagar upazila. Deeper and landwards intrusion of saline water occurs through various tidal rivers in the coast. With the tidal effect, saline water enter into the interior part of the area through Raymangal, Kalindi, Kobadak, Madar, Kholpetua, Arpangachia, Malancha, Hariabhanga and Chuna rivers (National Encyclopaedia of Bangladesh) and their tributaries and ultimately soil of the area become salinity affected. Salinity intrusion in water is seasonal which becomes aggravated in the dry season. The water salinity is normally flushed during monsoon, but soil salinity cannot be fully removed. The impacts of salinity on environment of the area are very high. People suffer severely from drinking water unavailability.

\subsubsection{River Bank Erosion}

Most of the parts of the coastal zone of Bangladesh are erosionprone (Sarwar and Woodroffe 2013; Sarker M. H 2013a). River bank erosion is a natural problem of the Shy amnagar upazial. The main rivers of the area are the Kholpetua, Kobadak, Kalindi, Malancha and Chuna. A change of river boundary is the aftermath of river bank erosion. It has widespread effects on human settlement and agricultural land. There are displacement and socio economic impact due to river bank erosion too. The most affected unions are Burigoalini, Munshiganj, Gabura and Padmapukur compare to erosion status in 2009. Erosion along the banks of the rivers causes a reduction in total area of cultivable land, resulting in a reduced agricultural production. Eroded soil settles down on the bed of the rivers, causing siltation.

\subsubsection{Flood}

Shyamnagar Upazila is flood-prone area. Overflow in the Kholpetua, Kobadak, Kalindi, Malancha and Chuna Rivers cause flood in the region. Generally, flood in this area remain within tolerable limits, but occasionally, it may be highly devastating. In general monsoon, inundation happens every year at nearby river side area. Sometimes, prolonged flood happens in 2/3 years. It has negative impacts on crops, livestock and fisheries. It affects the overall development activities. On the contrary, sedimentation from the flood water promotes to increase crop production. Flood not only affects agriculture crops, but also housing, road network, educational institutes and health infrastructures. Shy amnagar upazila was affected by devastating floods in the year of 1988, 1998, 2004 and 2010.

\subsubsection{Degradation of Wetland Ecosystems}

Wetlands support fisheries and aquatic biodiversity of the upazila. It acts as natural breeding ground for fish and other aquatic organisms. It also provides means of water transportation during rainy season. Wetland ecosystems of the upazila are decreasing day by day. Major elements of destruction are siltation, building infrastructure with inadequate drainage facilities, salinity intrusion, destruction of mangrove forest, wetland filling, water hyacinth, drying up of wetlands etc. In addition, people are converting low lying areas of the upazila for multipurpose commercial uses. Conversion of natural wetland into other uses of housing, road network, industry or aquaculture is important issues to be considered in land use.

Salinity intrusion in the upazila has changed ecology and ecosystems of wetlands in Shyamnagar upazila. Affected habitats have been destroyed by saline water leading to loss of biodiversity.

\subsubsection{Siltation}

Siltation in the bed and surrounding area of the Raymangal, Kalindi, Kobadak, Madar, Kholpetua, Arpangachia, Malancha, Hariabhanga and Chuna rivers (National Encyclopaedia of Bangladesh) is a common problem of the area. Siltation in the river causes the raising of its bed that affects navigation and the flow of water itself. Over a few decades, there have been significant changes in physical features and ecology of floodplains and rivers due to siltation. Beds of the rivers and 
nearby canals have been silted up that reduced water carrying capacity of rivers. Excessive sediment loads are deposited in the rivers and their tributaries that causes flood during monsoon and deposit sediments in adjacent low lying areas and wetlands of the upazila. Almost all unions of the upazila have been affected by different degrees of siltation.

\subsection{Major Anthropogenic Causes}

\subsubsection{Conversion of Agricultural Land into Shrimp Farm}

Shrimp farming in Bangladesh has been recognized as a part of the Blue Revolution. Shrimp is the second largest source of earning foreign currency. Coastal aquaculture is mainly based on shrimp cultivation. In parallel with its large contribution to local and national economy, it has already caused significant damages to the local ecosystems. During the last few decades shrimp aquaculture, particularly the black tiger shrimp (Bagda) has been a major component in the development of our national economy.

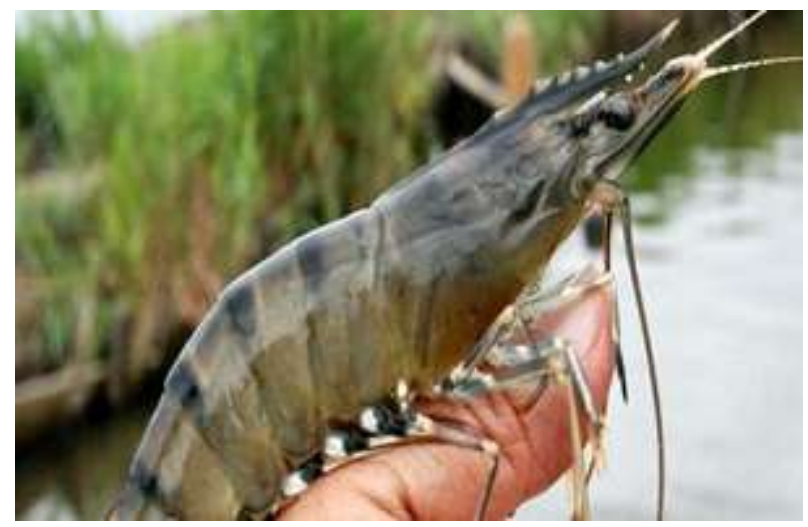

Figure 7. Shrimp (Bagda) culture activities

Mangrove forest is considered as a home of important coastal and marine biodiversity. It is an ideal breeding ground for fish and shrimp. These resources along southern parts of Shy amnagar upazila are being cleared off mainly because of the conversion of the land for shrimp cultivation. Due to increasing demand and satisfy the demand of particular interest group of stakeholders, both agricultural land and mangrove vegetation are converted into unauthorized expansion of shrimp (Penaeus monodon) cultivation.

There is a great risk of environmental degradation for shifting this land use pattern, which losses the soil fertility that might not be restored in near future even if the farmers intend to go back for agricultural production. Most importantly, the nature of coastal green belt is destroyed. As a result, the barrier to natural hazards like cyclones, storm surges, etc. would be at grave risk Human interventions, like rapid and unauthorized expansion of shrimp farming are considered as serious concern for environmental degradation of the upazila. Shrimp culture activities are shown in figure 7 .

\subsubsection{Expansion of Settlement, Infrastructure and Industries}

Rural settlements have been grown rapidly due to increased population pressure. Most of the fertile agricultural land along the roads and the surrounding areas already been converted into housing, market, other settlements, etc. Rapid settlement and infrastructures have been established in last 10 years in Shy amnagar Sadar, Bhurulia and Ishwaripur unions. Because of high demand, the land value has been increased tremendously, but unfortunately, it could not prevent this trend of unplanned uses of land.
Settlement development is a great cause for land use conversion. The inhabitants neither aware about planned township nor they care the environmental consequences. On top of that, roads and infrastructures are gradually developed everywhere within the upazila. So, the land use pattern is changing rapidly. Rapid and indiscriminate expansion of housing is one of the great challenges to protect agriculture land from being converted.

\subsubsection{Brick-fields}

Bricks have been used for various infrastructural activities in the upazila. With growing needs of housing, business, offices, transport networks and other construction activities, the demand for bricks has been increased at a faster rate. In order to supply demanded bricks, many brickfields were established in Shy amnagar upazila. There were only about 5 brick-fields in the upazila in 2009. But, numbers of brickfields are about 12-14 in 2015. Highest numbers of brickfields have been observed in Ishwaripur and Shy amnagar unions.

Generally, brickfields are constructed in medium high land near the road side. These are fertile agricultural land where farmers can grow two or three crops in a year. Newly established brickfields converted fertile agriculture land to non-productive area. Agriculture land in rapidly changing area in Ishwaripur and Shyamnagar unions have been converted to brick-field. Brick making industries cause land degradation for other agriculture field too. Brick-fields are major agents for topsoil degradation and environmental pollution. Bricks are made by collecting soils from a depth of about 1 to $2 \mathrm{~m}$ from agricultural land. With the increase in brick production, the destruction of fertile top-soil are taking place expanding the affected areas.

A total of 14 brick-fields in the upazila burn more than 100 tons of fire wood. This huge amount of wood burnt by brick-field cause large scales forest destruction. The concentrations of greenhouse gases in the atmosphere are increased by emissions from brick burning. Evolved heat damages the forest and

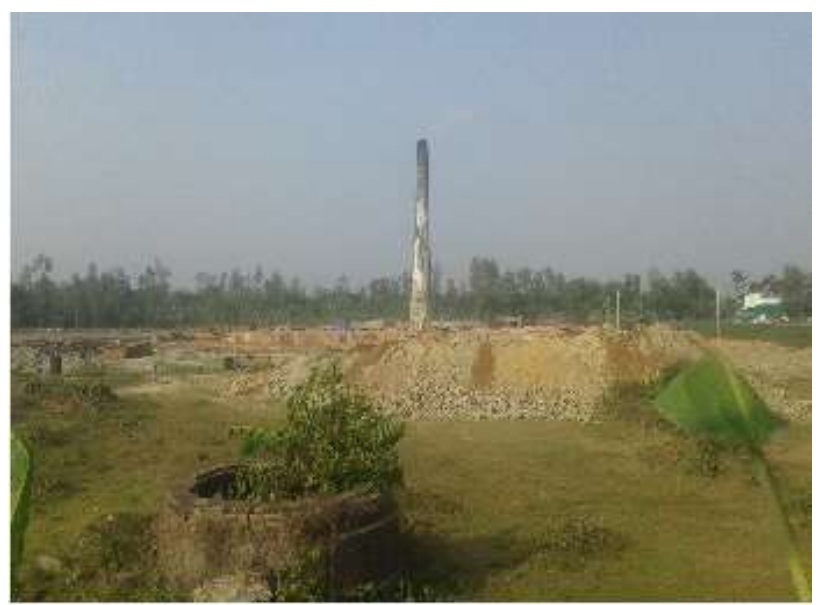

Figure 8. Agriculture land converted to brick-field

vegetation surrounding the brickfields and ultimately degrades the natural ecosystem.

Brick kilns are also polluting the air in rural area. Emission of huge quantity of toxic elements from brick kilns is causing serious health hazards. The brick kilns emit toxic fumes containing high concentration of carbon monoxides and oxides of sulphur. These chemical compounds are harmful to eye, lungs and throat of human being. Smoke and dust pollute the air of the surrounding areas that affect human settlements, educational institutions, office, market places etc. 


\subsubsection{Degradation of Coastal Forest}

Tree cover is an important land use subset in Shyamnagar Upazila. Indiscriminate felling of undersized trees declined tree cover. It exacerbates soil erosion and organic carbon loss. Increased population creates serious threat to forest resources. Tree cover destruction reduces carbon absorption and enhances global warming.

Anthropogenic factors are mostly responsible for deforestation. Tree covers are cleared for the expansion of human settlements and construction of roads and infrastructures for other commercial uses. Native species of plants, bushes and village forest are being cleared off because of the unplanned expansion of human settlements, brickfields, roads and infrastructures and changes of land use pattern etc. Illegal cutting for timbers and firewood are major driving forces for declining forest resources. Other factors responsible for the destruction of the forests are the uses of forest products as fuel. Cutting of trees for timbers and firewood are major factors for declining the forest resources.

\subsubsection{Improper Land Uses}

Land is the finite resource for most human activities including agriculture, industry, forestry, energy production, settlement, recreation, and water catchment and storage. The rapid population growth and the process of urbanization have resulted into changing land use pattern. Improper land use straightly affects the flora and fauna habitat and thus impacts biodiversity. Improper land use causes various forms of land degradation resulting in a reduced agriculture production. Land is a fundamental factor of production and has been tightly coupled with the economic growth. Land comprising soil, water and associated plants and animals are precious resources for the subsistence and survival of human being. However, optimum outputs from land resources cannot be obtained because of improper land uses. In order to improve the economic condition of the area without further deteriorating the bio-environment, every bit of the available land has to be used in the most rational way.

\subsubsection{Sundarbans Impacts Zone (SIZ)}

The Sundarbans is the largest single chunk of mangrove forests in the world. The physiography of the forest is dominated by deltaic formations that include innumerable drainage lines associated with surface and subaqueous levees, splays and tidal flats. There are also marginal marshes above mean tide level, tidal sandbars and islands with their networks of tidal channels, subaqueous distal bars and proto-delta clays and silt sediments.

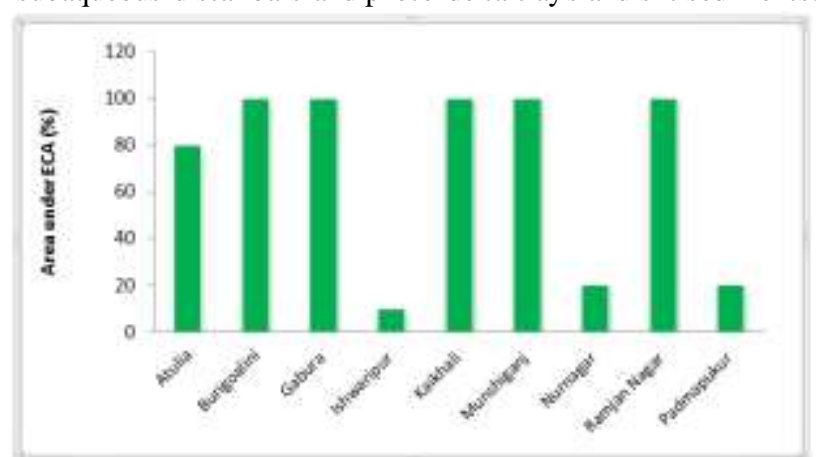

Figure 9. Union-wise Ecologically Critical Area (\%)

The floor of the Sundarbans varies from $0.9 \mathrm{~m}$ to $2.11 \mathrm{~m}$ above sea level. Shared between two neighboring countries, Bangladesh and India, the larger part $(62 \%)$ is situated in the southwest corner of Bangladesh. Shyamnagar upazila also covers a part of the Sundarbans (already described in study area). Considering the importance for the protection of the natural forests, a $10 \mathrm{~km}$ periphery buffer around the forest of Sundarbans has been declared as Ecologically Critical Area (ECA) by the Department of Environment (DoE) of Bangladesh Government in 1999 under the Environment Conservation Act 1995 (MoEF 1999). All parts of Burigoalini, Gabura, Kaikhali, Munshiganj and Ranjan Nagar unions and parts of Atulia, Ishwaripur, Nurnagar and Padmapukur unions of Shy amnagar fall under this ECA. However, this sensitive area continues to suffer due to over exploitation of resources from the mangrove forests.

The natural drainage in the upstream areas, other than the main river channels, is everywhere impeded by extensive embankments and polders. The Sundarbans was originally measured (about 200 years ago) to be of about $16,700 \mathrm{~km}^{2}$. Now it has dwindled to about $2 / 3$ of the original size. The total land area today is $4,143 \mathrm{~km}^{2}$ (including exposed sandbars: 42 $\mathrm{km}^{2}$ ) and the remaining water area of $1,874 \mathrm{~km}^{2}$ encompasses rivers, small streams and canals. Rivers in the Sundarbans are meeting places of salt water and freshwater. Thus, it is a region of transition between the freshwater of the rivers originating from the Ganges and the saline water of the Bay of Bengal (Wahid et al. 2002).

\subsubsection{Loss of Biodiversity}

Shy amnagar Upazila is very rich in biodiversity. Almost every village of the Upazila was dominated by a good number of indigenous species of plants, animals, birds, mammals, amphibians and reptiles etc. However, information collected during the consultation with the local people and field visit explored that the biodiversity status of the upazila is in a decline trend.

The upazila was rich in various species of native and migratory birds, in past decades. Because of environment degradation and absence of natural forest, big and medium sized carnivorous animals are already lost; leaving a number of other smaller animals. They are again threatened for their survival and gradually becoming extinct due to loss of their habitats. The upazila already experienced the extinction of many important flora and fauna while a number of the remaining others are vulnerable to extinction. Lists of rare species, indicated by local people have been presented in table 5 .

Table 5. List of Rare Species in Shy amnagar Upazila

\begin{tabular}{|l|l|}
\hline \multicolumn{1}{|c|}{ Types } & \multicolumn{1}{c|}{ Name of Rare Species } \\
\hline Tree & Neem, Chalta, Jackfruit, Bamboo \\
\hline Animal/Bird & Crocodile, Shark, Shishu, Vulture \\
\hline Fish & Koi, Magor, Shing, Boal, Gozar, \\
\hline
\end{tabular}

\subsubsection{Environmental Factors at a Glance}

The environmental variables, issues and concerns that affect the Shy amnagar upazila have been sketched. Additionally, detailed environmental factors, impacts and sector wise spatial distribution have been shown in table 6 . 
Table 6. Detailed environmental factors, impacts and sector wise spatial distribution.

\begin{tabular}{|c|c|c|c|c|}
\hline Emvironmental Facinn & Stre live & Ifigh & Steitrrate & Ian \\
\hline Wwer Salinity & s & $w$ & & \\
\hline Seil Saliairy & $\sqrt{2}$ & W & & \\
\hline Sllorimp Cher & $n$ & $\checkmark$ & & \\
\hline Strong Tule & & w & 8 & \\
\hline Detornatatian & $\sqrt{3}$ & $\gamma$ & 8 & \\
\hline Lewar absadivenieg & $\sqrt{2}$ & & W & \\
\hline Less of thaticat & & 8 & n & \\
\hline Seas Cultars & $\frac{1}{2}$ & $\sqrt{x}$ & $\gamma$ & \\
\hline \multicolumn{5}{|l|}{ 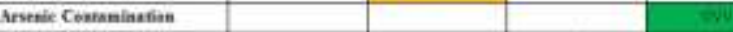 } \\
\hline Ordard Fandeg & & & 8 & 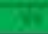 \\
\hline Fthih Caltivation: & & $\sqrt{1}$ & & \\
\hline \multicolumn{5}{|l|}{ Chenteral tim } \\
\hline Sand Extractien & & & & sw \\
\hline Secultement Espansos & & $\nabla$ & 78 & \\
\hline sitratiea & & & $\sqrt{W}$ & $\sqrt{1}$ \\
\hline \multicolumn{5}{|l|}{ Sor neater Winetrarm } \\
\hline Cyclaner & & & & 37 \\
\hline Raver llaki Ematian & & w & & $\sqrt{2}$ \\
\hline Woter buine & & 8 & 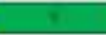 & $\sqrt{1}$ \\
\hline Siltatien & & Wh & - & \\
\hline \multicolumn{5}{|l|}{ Monopon fleod } \\
\hline Droeght & & & & 30 \\
\hline
\end{tabular}

\section{CONCLUSION AND RECOMMENDATIONS}

An environment assessment of Shy amnagar upazila was done based on integrated approach of remote sensing and GIS, field survey, group discussion, community meeting, key informant interview and literature review. The study explored various natural and anthropogenic hazards and/or disasters in the upazila. Major issues addressed in Shyamnagar upazila are i) cyclone and tidal surges, ii) salinity intrusion, iii) river bank erosion, iv) flood, v) siltation, vi) wetland degradation, vii) unplanned expansion of housing, infrastructure and industries in agriculture land, viii) brick-field, ix) degradation of Ecologically Critical Area (ECA), and x) loss of biodiversity.

In Shyamnagar, there are enormous potentials of using environmental resources and ecosystem services. There are wide scopes of reforestation, afforestation, sustainable agricultural practices, environment friendly shrimp cultivation, and ecotourism. In addition, archaeological heritage of the upazila is rich in historical sculptures. In addressing environmental issues, key stakeholders and communities can be sensitized with land use. A better inter agency coordination is essential for the implementation of land use.

Land use is of prime importance for land suitability mapping and to prevent environmental degradation of valuable land resources and restore the degraded land where possible. Preparation of land use map and their implication would act as useful tool to safeguard the environment and resolve conflicts of interest between the user groups and the line agencies. Prior initiative with preventive measure taken locally and in Government level can mitigate the environmental degradation. Land degradation could be averted through a balanced environmental management plan with people's participation and proper land use.

\section{ACKNOWLEDGEMENT}

The authors are grateful to authority of National Land Zoning Project (NLZP) for providing available data sets for completing the research study.

\section{REFERENCES}

ArcGIS user guide.

Campbell, J. B. (1996), Introduction of Remote Sensing, $2^{\text {nd }}$ edition, London: Tay lor and Francis.

Government of Bangladesh GoB (2008), Cyclone Sidr in Bangladesh: Damage, Loss and Needs Assessment for Disaster Recovery and Reconstruction, Economic Relations Division MoF, Report prepared by the Government of Bangladesh (GoB) and assisted by the International Development Community with Financial Support from the European Commission.

MoEF (1999), Ecological Critical Area Gazette Notification, No: 4/7/87/99/263, Department of Environment, Ministry of Environment and Forest (MoEF), Government of Bangladesh, Dhaka.

National Ency clopaedia of Bangladesh

Sarker M. H. et.al, (2013a), Mapping of Coastal Morphological Changes of Bangladesh using RS, GIS and GNSS Technology; Journal of Remote Sensing and GIS, ARSGISO, Page 27-34,

Sarker M.H. et.al, (2013b), Monitoring Cyclone Aila and its impact over Coastal Region of Bangladesh; J. Environ. Sci. \& Natural Resources, v25(1): p2632,

Sarwar M.G.M (2016). An Overview of Bangladesh Disasters, In S. Parasuraman S and Unni Krishnan India Disasters Report 3 (IDR 3), Oxford University Press, New Delhi. (In press).

Sarwar M.G.M, Woodroffe C.D (2013). Rates of shoreline change along the coast of Bangladesh, Journal of Coastal Conservation.

Sarwar M. G. M, Khan M. H (2007). Sea Level Rise: A Threat to the Coast of Bangladesh, International Asian forum 38 (3-4), pp.375-397.UN 2010. Cyclone Aila: Joint UN Multi-sector Assessment and Response Framework, United Nations, Dhaka, Bangladesh.

Stach, N., Salvado, A, Petit, M., Ingrassia, F., Joubert, P. Deshayes, M. (2007) Monitoring land use and land cover changes in French Guiana by optical remote sensing. Forestsat 2007 Conference (Forest and remote Sensing: Methods and Operational Tools). Montpellier, France, Nov. 2007.

Wahid, A., Hameed, M. \& Rasul, E. (2002), Salt-induced injury symptom, changes in nutrient and pigment composition and yield characteristics of moonbeam: International Journal of Agricultural Biology, 6, 1143-52, ISSN 15608530.

Weng, Q. (2001). A remote sensing-GIS evaluation of urban expansion and its impact on surface temperature in the Zhujiang Delta, China: International Journal of Remote Sensing, Forthcoming. 